SCIENTIFIC REPORT

\title{
Incidence and severity of keratoconus in Asir province, Saudi Arabia
}

\author{
A A Assiri, B I Yousuf, A J Quantock, P J Murphy
}

Br J Ophthalmol 2005;89:1403-1406. doi: 10.1136/bjo.2005.074955

Aim: To assess the incidence and associated signs and symptoms of patients with keratoconus in Asir Province, Saudi Arabia.

Methods: 125 new keratoconus patients $(51$ male, 74 female; mean age 18.5 (SD 3.8) years; range 8-28 years) were recruited from referrals to the department of ophthalmology, Asir Central Hospital, over a 1 year period. Age, visual acuity, and keratometry were recorded along with clinical signs and symptoms.

Results: The incidence of keratoconus in Asir Province is 20 cases per 100000 population. Also, the disease severity is high, as indicated by an early mean age (17.7 (3.6) years) with advanced stage keratoconus. Visual acuity, with either spectacles or rigid contact lenses, was 6/12 or better in $98 \%$ of eyes measured. Just over half $(56 \%)$ of patients had atopic ocular disease. $16 \%$ of patients had a positive family history of the disease and $16 \%$ had atopic dermatitis (eczema and/ or vitiligo).

Conclusion: The incidence and severity of keratoconus in Asir Province, Saudi Arabia, is high with an early onset and more rapid progress to the severe disease stage at a young age. This might reflect the influence of genetic and/or environmental factor(s) in the aetiology of keratoconus.

$\mathrm{K}$ eratoconus is a non-inflammatory, acquired ectasia that causes progressive, changeable, myopic astigmatism. Mostly it occurs bilaterally but develops asymmetrically, ${ }^{1}$ with an onset at puberty and progression over a period of 7-20 years. ${ }^{23}$ Incidence ranges from 1.4 to 600 cases per year per 100000 population. ${ }^{4-9}$ Most reports have considered white populations, with some studies suggesting an influence of ethnic origin on the incidence and age at onset. ${ }^{10}{ }^{11}$

Previous studies on keratoconus in Saudi Arabia are very limited. ${ }^{12}{ }^{13}$ This paper reports a prospective study that assesses the incidence rate and associated signs and symptoms of patients with keratoconus in Asir Province, Saudi Arabia.

\section{METHODS}

All patients attending the department of ophthalmology, Asir Central Hospital, Saudi Arabia, between May 2001 and April 2002, who were suspected of having keratoconus, were recruited, as were patients newly diagnosed with keratoconus but attending other tertiary hospitals in Asir Province. In total, 125 patients ( 240 eyes) were recruited, comprising 51 males and 74 females (mean age 18.5 (SD 3.9) years; range 8-28 years). All subjects were examined for case history, visual acuity, keratometry, refraction, and ocular signs. Diagnosis was made on the basis of changes in best corrected visual acuity, familial keratoconus, an irregular surface evidenced by distorted corneal curvature, keratometry, scissoring of the retinoscopic reflex, or irregularity in the red reflex on direct ophthalmoscopy. Clinical signs included at least one of the following: central corneal thinning, apical stromal scaring, Vogt's striae, Fleischer's ring, and Munson's sign. Unusual cases for which a diagnosis could not be established with confidence were excluded. All data were analysed using the statistical software package SPSS 12 (SPSS Inc, USA).

\section{RESULTS}

The incidence of keratoconus in Asir Province was calculated using the area population for those aged between 5 and 29 years (654 163), ${ }^{14}$ because the disease usually develops within this age range, and because the study's age range was also of this order ( $8-28$ years). With this calculation, the incidence was 20 cases per 100000 . Mean age at diagnosis was 17.7 (3.6) years for males (range 8-24 years) and 19.0 (3.8) years for females (range 12-28 years) (fig 1).

Visual acuity measurements indicated that uncorrected vision decreased with increasing disease severity and was classified on the basis of average keratometry reading (table 1). As corneal astigmatism and curvature increased vision decreased. However, visual acuity (VA) values were variable even for patients at the same disease stage. The data also show that the overall steepening of the cornea produces a greater change in VA than does any increase in astigmatism (fig 2).

Depending on the stage of the disease, VA was improvable for 108 eyes with spectacles, and 132 eyes with rigid contact lenses (table 2). With spectacles, $33 \%$ of eyes achieved a corrected VA of $6 / 6$ or better, with $100 \%$ achieving $6 / 12$ or

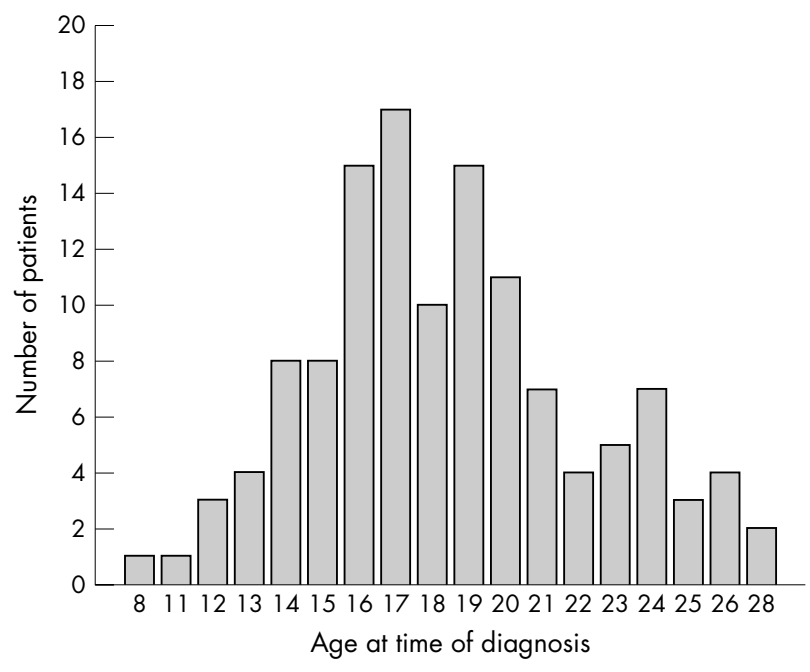

Figure 1 Age distribution of the patients enrolled in the study at the time of ophthalmological diagnosis. 
Table 1 Vision varies with severity of keratoconus, but is influenced by the degree of astigmatism and myopia

\begin{tabular}{llcc}
\hline \multirow{4}{*}{ Visual acuity } & \multicolumn{3}{l}{ Average K reading } \\
\cline { 2 - 4 } & $\leqslant \mathbf{4 8} \mathbf{D}$ & $>\mathbf{4 8 - 5 4} \mathbf{D}$ & $>\mathbf{5 4} \mathbf{D}$ \\
\hline$\leqslant 6 / 24$ & 57 & 21 & 2 \\
$>6 / 24 \leqslant 6 / 60$ & 34 & 68 & 18 \\
$>6 / 60$ & 3 & 13 & 24 \\
Overall & 94 & 102 & 44 \\
\hline
\end{tabular}

better. With rigid contact lenses, $93 \%$ of eyes achieved $6 / 6$ or better, and $97 \% 6 / 12$ or better.

The severity of keratoconus was assessed from keratometry reading, in the worse affected eye, and patients' age at diagnosis. ${ }^{15}{ }^{16}$ Based on the keratometry results, the keratoconus population was divided into three groups: early $\leqslant 48 \mathrm{D}$, moderate 48-54D, and advanced $>54 \mathrm{D}$ (fig 3).

Twenty of $125(16 \%)$ patients had eczema, asthma, and/or vitiligo. Another 20 patients had a family history of keratoconus. There was no evidence of tapeto-retinal degeneration or Reiger's anomaly. Further, we encountered no systemic diseases such as Down's, Marfan's or EhlersDanlos syndromes. Seventy of $125(56 \%)$ patients had a positive ocular history for one or more of the following keratoconus associated factors: eye rubbing, ocular allergy, tearing, ocular redness, or vernal keratoconjunctivitis (fig 4). Five patients between the ages of 6 and 12 years reported all five symptoms, and three of these also had a family history of keratoconus.

\section{DISCUSSION}

The ability to describe the incidence of a disease is important for predicting current and future clinical needs, and for establishing disease characteristics in a particular population. This study found an incidence of keratoconus in Asir Province, Saudi Arabia, to be 20 per 100000 based on referrals to the provincial, tertiary level specialist clinic. This compares with 1 per 100000 in the United Kingdom, ${ }^{7} 2$ per 100000 in Minnesota (USA), ${ }^{4} 2.2$ per 100000 in Finland, ${ }^{5} 2.5$ per 100000 in Holland, ${ }^{8}$ and 50 per 100000 in New Zealand. ${ }^{6}$

The incidence of keratoconus in our cohort is comparable to that of 20-25 per 100000 in Asian populations living in the United Kingdom but higher than for British white people. ${ }^{10} 11$ Environmental influences for these groups will presumably be similar and the higher number of consanguineous marriages among Muslims has been proposed as a cause of the increased incidence. ${ }^{10}{ }^{11}$ Previous reported incidences for a family history of keratoconus in white populations are $6 \%,{ }^{17}$ $8.8 \%,{ }^{18}$ and $23.5 \%,{ }^{19}$ compared to $16 \%$ in this study. In one
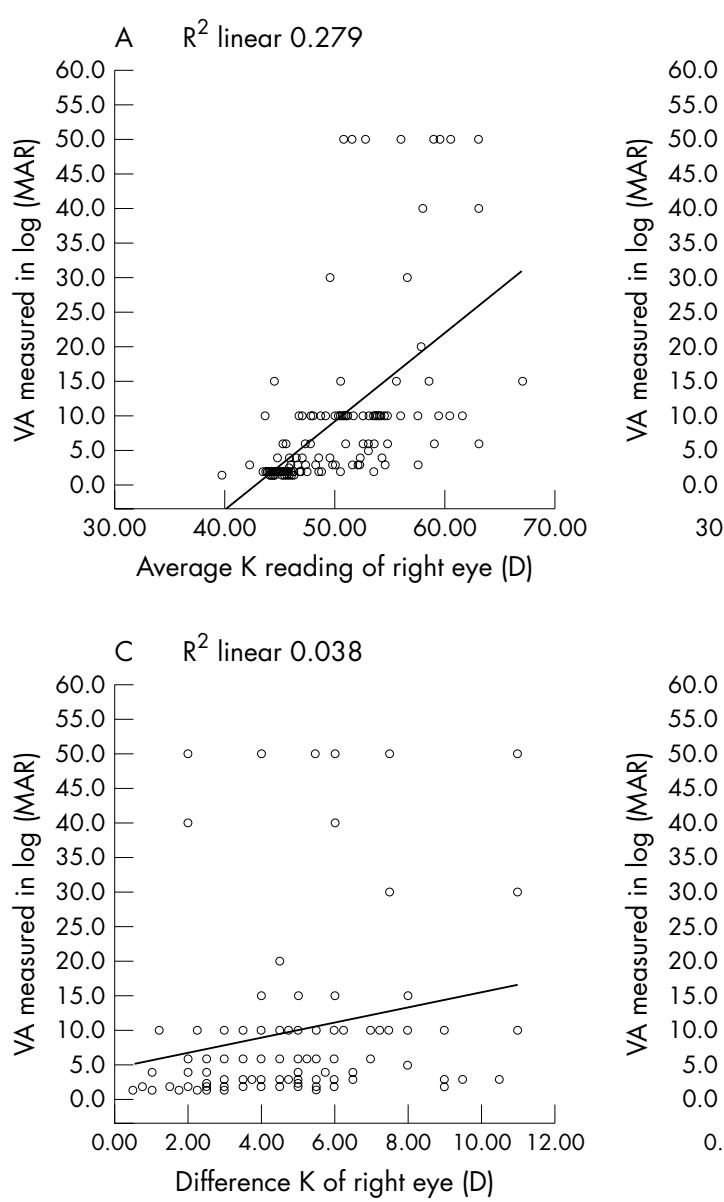

Figure 2 Scatter plot illustrating vision against keratometry measurements. (A, B) Vision decreases with increasing corneal curvature $\left(r^{2}=0.28\right)$. (C, D) Vision decreases with increasing corneal astigmatism, although with only a weak relation: right eye $\left(r^{2}=0.04\right)$ left eye $\left(r^{2}=0.05\right)$.

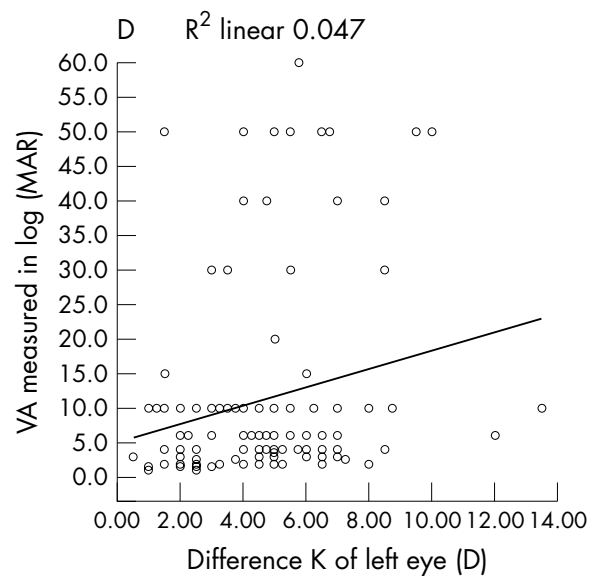


Table 2 Distribution of corrected visual acuity with spectacles and rigid contact lenses

\begin{tabular}{|c|c|c|c|c|}
\hline \multirow[b]{2}{*}{$\begin{array}{l}\text { Visual acuity } \\
\text { level }\end{array}$} & \multicolumn{2}{|c|}{ With spectacle correction } & \multicolumn{2}{|c|}{ With rigid contact lenses } \\
\hline & $\begin{array}{l}\text { No } \\
\text { (eyes) }\end{array}$ & Cumulative & $\begin{array}{l}\text { No } \\
\text { (eyes) }\end{array}$ & Cumulative \\
\hline $6 / 4.5$ & - & $0 \%$ & 7 & $5.3 \%$ \\
\hline $6 / 5$ & - & $0 \%$ & 6 & $9.85 \%$ \\
\hline $6 / 6$ & 36 & $33.3 \%$ & 110 & $93.18 \%$ \\
\hline $6 / 7.5$ & 8 & $40.7 \%$ & - & $0 \%$ \\
\hline $6 / 9$ & 22 & $61.1 \%$ & - & $0 \%$ \\
\hline $6 / 12$ & 42 & $100 \%$ & 5 & $96.97 \%$ \\
\hline $6 / 15$ & - & $0 \%$ & 3 & $99.24 \%$ \\
\hline $6 / 18$ & - & $0 \%$ & 1 & $100 \%$ \\
\hline Total & 108 eyes & $100 \%$ & 132 & $100 \%$ \\
\hline
\end{tabular}

family reported here, of seven children, four had keratoconus in at least one eye.

We should consider the possibility that environmental or geographical factors may have contributed to the incidence and severity of keratoconus found in this study. Asir Province is a mountainous region and the majority of patients in our study (95\%) live at an altitude of 3000 metres on average. Here, people are likely have a greater exposure to ultraviolet, given that levels increase with altitude by approximately $10 \%$ for every 1000 metres of elevation. ${ }^{20}$ Ultraviolet light has previously been linked to keratoconus. Some investigators have proposed that keratoconic corneas have underlying defects in their ability to process accumulated reactive oxygen species, and that this might have a role in the disease pathogenesis. ${ }^{21} 22$ The effect of ultraviolet light has also been used to explain the high incidence of keratoconus in New Zealand, which has a white population similar to the United Kingdom, but, because the ozone layer is thinner, a greater ultraviolet background. ${ }^{19}$ This link, however, could not be proved definitively since it was not possible to assess actual ultraviolet dosage. Thus, the role of ultraviolet requires further study before it can be determined as a risk factor for keratoconus in patients from Asir Province, Saudi Arabia.

An early age of onset was recorded in this study ( 18.5 years) with approximately three quarters of our patients $(74.4 \%)$ presenting before the age of 20 years (in the Collaborative Longitudinal Evaluation of Keratoconus (CLEK) study only $4 \%$ presented by this $\operatorname{time}^{17}$ ). Investigations in white populations have reported a higher age at the time of study (mean 27 years) suggesting a later disease onset. ${ }^{4} 10112324$ Our results are comparable to the mean presentation age in Asian keratoconus patients of

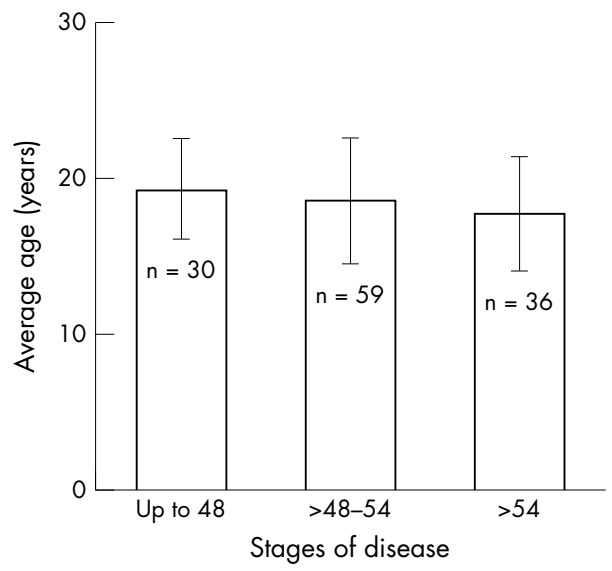

Figure 3 Age at the time of ophthalmological diagnosis for each keratometry group. Error bars show mean ( $\pm 1.0 \mathrm{SD})$.
20.2 years, ${ }^{25} 21.5$ years, ${ }^{10}$ and 22.5 years. ${ }^{11}$ Increased disease severity in our subjects is revealed by average keratometry readings, with 94 eyes (39.2\%) in the early stage, 102 eyes $(42.5 \%)$ in the moderate stage, and 44 eyes $(18.3 \%)$ in the advanced stage. Moreover, 37 eyes in the advanced stage $(84 \%)$ belonged to subjects 20 years or under, more than the $67 \%$ reported elsewhere. ${ }^{23}$

VA decreases as corneal curvature and astigmatism increase (fig 2). However, the correlations are not strong because of the variable influence of the amount, regularity, and obliqueness of the astigmatism, the level of progressive myopia, the scar type, morphology of the cone, and extent of any atopic disease. This indicates that the VA of a keratoconus patient does not present an accurate picture of the progress of the disease. Clinically this is seen when a keratoconic patient presents with an equal bilateral stage of the disease, with a VA in each eye that is manifestly different. Contact lenses generally provided the best means of improving vision, with $93 \%$ of eyes achieving $6 / 6$ or better. Only one third of spectacle wearers achieved this level.

Atopic diseases (asthma and atopic dermatitis) have been suggested as aetiological components of keratoconus. Here, we did not find a strong pattern of association with only $16 \%$ of our patients reporting any form of atopy. This compares with an average of $35 \%$ reported by others. ${ }^{26}{ }^{27} \mathrm{~A}$ link between allergy and eye rubbing has been reported, ${ }^{28}$ with atopic patients thought to develop keratoconus as a result of eye rubbing. ${ }^{29}$ Karsersas and Ruben, ${ }^{30}$ for example, found a history of eye rubbing in $66 \%$ of their keratoconus patients, while Weed and McGhee ${ }^{31}$ indicated that $48 \%$ of keratoconus patients rubbed their eyes. In the current study, 49 (39.2\%) and $56(44.8 \%)$ patients complained of allergy and rubbing,

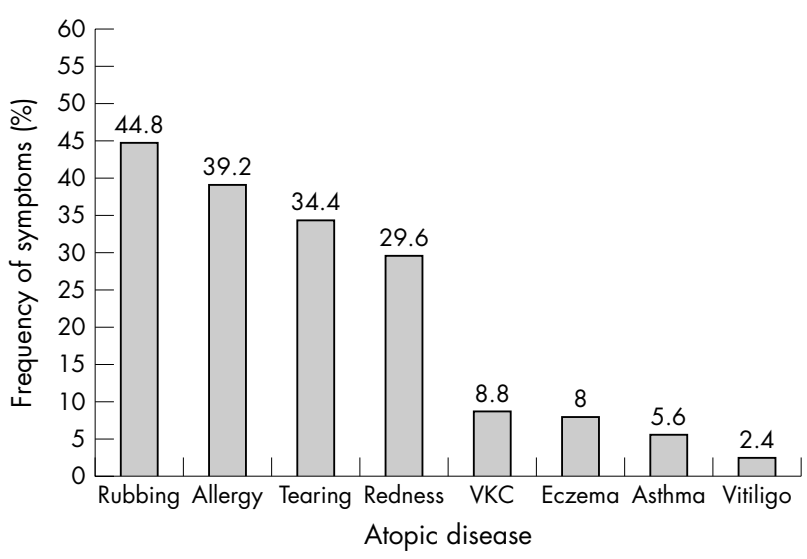

Figure 4 Percentage of patients with ocular signs and symptoms accompanying keratoconus. 
respectively. In addition, 15 of $30(50 \%)$ patients in the early stage, 32 of $59(54 \%)$ patients in the moderate stage, and 23 of $36(63.8 \%)$ patients in the advanced stage complained of both allergy and rubbing.

In conclusion, an early onset and increased severity of keratoconus was found in Asir Province, Saudi Arabia. This may be related to a combination of genetic and/or environmental factors. Clinically, contact lens correction should be considered earlier to maximise visual performance. The results have implications for keratoconus screening in Saudi Arabia, to improve early detection and treatment.

The work was done in accordance with the ethical rules of the Saudi Ministry of Health and Asir Central Hospital.

\section{Authors' affiliations}

A A Assiri, A J Quantock, P J Murphy, Cardiff University, School of Optometry and Vision Sciences, UK

A A Assiri, B I Yousuf, Asir Central Hospital, Department of Ophthalmology, Saudi Arabia

Supported by the Ministry of Health, and Asir Central Hospital, Department of Ophthalmology, Kingdom of Saudi Arabia.

Competing interests: none declared

Correspondence to: Abdullah M Assiri, Cardiff University, School of Optometry and Vision Sciences, Redwood Building, King Edward VII Avenue, Cathays Park, Cardiff CF10 3NB, UK; assiria@cf.ac.uk

Accepted for publication 6 June 2005

\section{REFERENCES}

1 Zadnik K, Steger-May K, Fink B, et al. Between-eye asymmetry in keratoconus. Cornea 2002;2:671-9.

2 Bennett ES. Keratoconus. In: Bennett ES, Grohe RM, eds. Rigid gas permeable contact lenses. New York: Professional Press, 1986:296-344.

3 Zadnik K. Keratoconus. In: Bennett ES, Weissman BA, eds. Clinical contact lens practice. Philadelphia: JB Lippincott, $1991 ; 45: 1-10$.

4 Kennedy RH, Bourne WM, Dyer JA. A 48 year clinical and epidemiological study of keratoconus. Am J Ophthalmol 1986;101:267-73.

5 Ihalainen A. Clinical and epidemiological features of keratoconus: genetic and external factors in the pathogenesis of the disease. Acta Ophthalmol 1986; 178(suppl):5-64.

6 Sabiston DW. The crazy cone. Austral J Ophthalmol 1978;6:43-5.

7 Duke-Elder S, Leigh AG. Keratoconus. In: Duke-Elder S, ed. System of ophthalmology, Vol 8, No 2. St Louis: Mosby, 1965:964-76.
8 Woodward EG. Keratoconus-epidemiology. J Br Contact Lens Assoc 1984;7:64-76.

9 Hofstetter HW. A keratoconic survey of 13,395 eyes. Am J Optom Arch Am Acad Optom 1959;36:3-11.

10 Pearson AR, Soneji B, Sarvananthan N, et al. Does ethnic origin influence the incidence of severity of keratoconus? Eye 2000;14:625-8.

11 Georgiou T, Funnell CL, Cassels-Brown A, et al. Influence of ethnic origin on the incidence of keratoconus and associated atopic disease in Asians and white patients. Eye 2004; 18:379-83.

12 Al-Towerki A, El-Sayed G, Al-Rajhi A, et al. Changing indications for corneal transplantation at the King Khalid Eye Specialist Hospital (1983-2002). Cornea 2004;23:584-8

13 Mahmood M, Wagoner M. Penetrating keratoplasty in eyes with keratoconus and vernal keratoconjunctivitis. Cornea 2000;23:468-70.

14 Ministry of Planning, Central Department of Statistics Population and Vital Statistics. Population Characteristics in the Kingdom of Saudi Arabia: demographic survey. Riyadh: Ministry of Planning, Central Department of Statistics Population and Vital Statistics, 2001:41.

15 Fowler WC, Belin MW, Chambers WA. Contact lenses in the visual correction of keratoconus. CLAO J 1988;14:203-6.

16 Carmichael TR, Ben-Smith GJ, Chopamba-Kamba A. Keratoconus associated with limbal vernal keratoconjunctivitis in African patients. S Afr Optom 2003;62:47-54.

17 Zadnik K, Barr JT, Mae O, et al. Bio-microscopic signs and disease severity in keratoconus. Cornea 1996;15:139-46.

18 Swan PG, Waldron HE. Keratoconus: the clinical spectrum. J Am Optom Assoc 1986:57:204-9.

19 Owens H, Gamble G. A profile of keratoconus in New Zealand. Cornea 2003;22:122-5.

20 Marin MJ, Sola Y, Tena F, et al. The UV index on Spanish Mediterranean coast. Photochem Photobio 2005; preprint. Published online Feb 2005.

21 Kenney C, Brown D. The cascade hypothesis of keratoconus. Cont Lens Ant Eye 2003;26:139-46.

22 Buddi R, Lin B, Atilano S, et al. Evidence of oxidative stress in human corneal diseases. J Histochem Cytochem 2002;50:341-51.

$23 \operatorname{Lim} \mathrm{N}$, Vogt U. Characteristics and functional outcomes of 130 patients with keratoconus attending a specialist contact lens clinic. Eye 2002;16:54-9

24 Owens H, Watters GA. An evaluation of the keratoconic cornea using computerised corneal mapping and ultrasonic measurements of cornea thickness. Ophthal Physiol Opt 1994;16:115-23.

25 Saini G, Saroha V, Singh $P$, et al. Keratoconus in Asian eyes at a tertiary eye care facility. Clin Exp Optom 2004;87:97-101.

26 Gasset AR, Houde WL, Garcia-Bengochea M. Hard contact lens wear as an environmental risk in keratoconus. Am J Ophthalmol 1978;85:339-41.

27 Rahi A, Davies $\mathrm{P}$, Ruben $M$, et al. Keratoconus and co-existing atopic disease. $\mathrm{Br} J$ Ophthalmol 1977;61:761-4.

28 McMonnies CW, Boneham GC. Keratoconus, allergy, itch, eye-rubbing and hand-dominance. Clin Exp Optom 2003;86:376-84.

29 Bawazeer AM, Hodge WG, Lorimer B. Atopy and keratoconus: a multivariate analysis. Br J Ophthalmol 2000;84:834-6.

30 Karseras AG, Ruben M. Aetiology of keratoconus. Br J Ophthalmol 1976;60:522-5.

31 Weed KH, McGhee CNJ. Referral patterns, treatment management and visual outcome in keratoconus. Eye 1998;12:663-8. 